\title{
Mesoporous Silica SBA-15-supported Norephedrine and Ephedrine as Heterogeneous Chiral Ligands
}

\author{
Myung-Jong Jin, "M. S. Sarkar, Vijay B. Takale, and Sang-Eon Park \\ Department of Chemical Engineering and Chemistry, Inha University, Incheon 402-751, Korea.*E-mail: mjjin@inha.ac.kr
} Received June 22, 2005

Key Words : SBA-15, Norephedrine, Ephedrine, Heterogeneous, Chiral ligand

Successful development of the homogeneous catalysts has been sometimes followed by attempts to attach the catalysts on an insoluble polymeric support. A suitably designed immobilized catalyst can retain the advantages of a heterogeneous catalyst in terms of simplified workup procedure and recyclization while maintaining reactivity and selectivity of a homogeneous catalyst. ${ }^{1}$ The immobilization of homogeneous species is of particular interest in the field of asymmetric catalysis since it is desirable to be able to regenerate and reuse expensive chiral catalysts. ${ }^{2}$ Polystyrene resin and silica gel have been most commonly used as insoluable supports for the immobilization of the catalysts. ${ }^{3}$ Recently, mesoporous silica SBA-15 with large uniform pore diameters and high specific surface areas have become of high interest as inorganic supports. ${ }^{4}$ Our interest in the field led to prepare SBA-15-supported ephedrine $\mathbf{1}$ and norephedrine 2 . Herein, we report our investigation on the asymmetric addition of diethylzinc reagent to aldehydes ${ }^{5}$ and on the asymmetric transfer hydrogenation of ketones mediated by the supported ligands. ${ }^{6}$

As shown in Scheme 1, (-)-ephedrine was anchored on SBA-15 silica in a similar procedure as for silica gelsupported ephedrine $1 .^{7}$ Treatment of SBA- 15 with an excess of (3-chloropropyl)triethoxysilane in refluxing toluene gave chloropropylated SBA-15. The free silanol group was endcapped by treatment with hexamethyldisilazane (HMDS). Reaction of the samples are summarized in Table 1. The surface area was decreased considerably in the chloro-
Table 1. Chracterization of SBA-15-supported chiral ligands

\begin{tabular}{cccc}
\hline & $\begin{array}{c}\text { Surface area } \\
\left(\mathrm{m}^{2} / \mathrm{g}\right)\end{array}$ & $\begin{array}{c}\text { Pore diameter } \\
(\mathrm{nm})\end{array}$ & $\begin{array}{c}\text { Loading amount } \\
(\mathrm{mmol} / \mathrm{g})\end{array}$ \\
\hline SBA-15 & 803 & 7.9 & - \\
$\mathbf{1}$ & 452 & 7.4 & 0.62 \\
$\mathbf{2}$ & 471 & 7.6 & 0.65 \\
\hline
\end{tabular}

propylation, but the pore diameter was not changed substantially during the modification steps. chloropropylated SBA-15 with 1.5 equiv. excess of (-)-ephedrine in refluxing toluene in the presence of 1 equiv of diisopropylethylamine afforded SBA-15-supported ephedrine 1. SBA-15-supported norephedrine 2 was also prepared from (-)-norephedrine by the same method. The degrees of functionalization were determined by weight gain or nitogen elemental analysis for the modified SBA-15. The characteristics of the two samples are summarized in Table 1. The surface area was decreased considerably during the modification, but the pore diameter was not changed substantially.

With the supported ephedrine $\mathbf{1}$ in hand, we examined its catalytic efficiency in asymmetric addition of diethylzinc to aldehyde in hexane. ${ }^{8}$ Aldehydes were converted to the corresponding $(R)$-secondary alcohols with moderate ee's in high yields. The results were compared to the data previously obtained with amorphrous silica gel-supported ephedrine. As can be seen in Table 2, SBA-supported ephedrine 1 gave much higher reaction rate and better

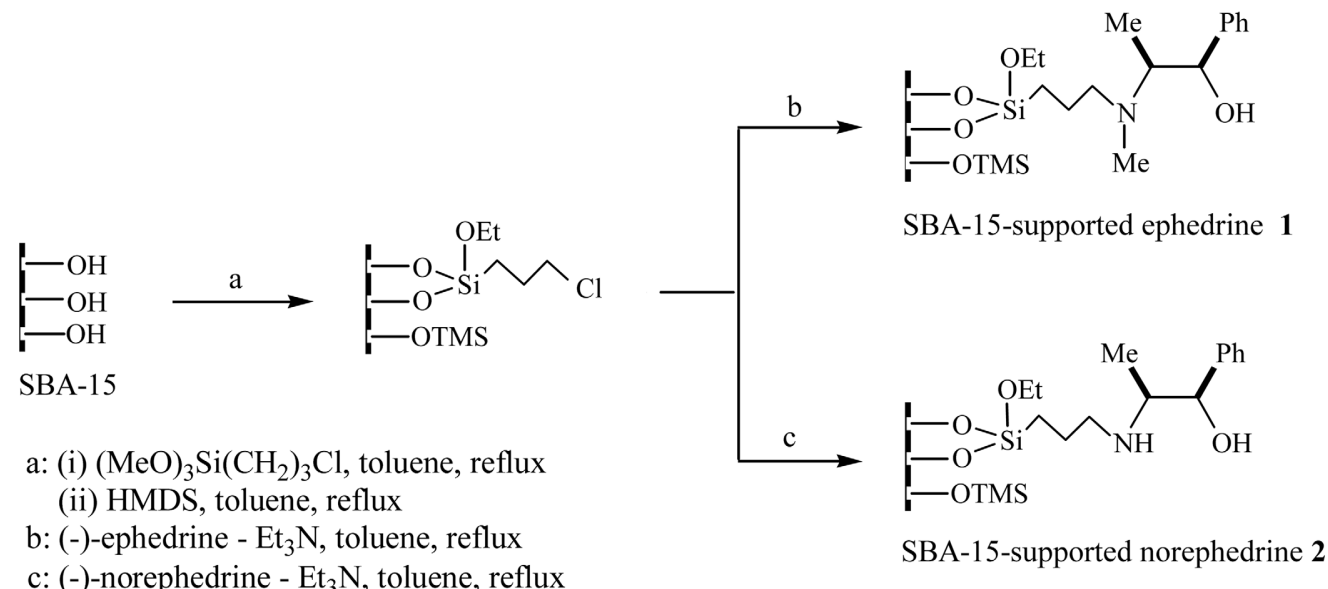

Scheme 1 
Table 2. Asymmetric addition of diethylzinc to aldehydes ${ }^{a}$

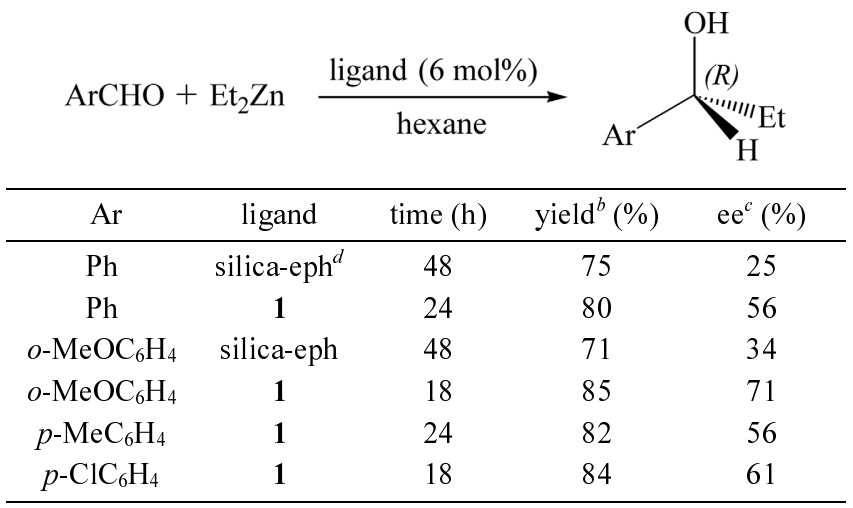

${ }^{a}$ Reactions were carried out in hexane at RT using 2 equiv. of $\mathrm{Et}_{2} \mathrm{Zn}$. Absolute configuration was assigned by the sign of the optical rotation. ${ }^{b}$ Measured as \%-conversion into the product by GC. ${ }^{c}$ Determined by HPLC analysis using chiralcel OD-H column. ${ }^{d}$ Silica-eph $=$ silica gelsupported ephedrine. ${ }^{7}$

asymmetric induction than silica gel-supported ephedrine. The improved outcome of the reaction seems to be attributed to crystalline structure of SBA-15. The SBA framework allows regular array of chiral catalytic sites on the pore surface. This leads to elegant site-isolation, which may result in enhanced enantioselecivity. In the case of $o$-methoxybenzaldehyde, enantioselectivity was greatly increased from $34 \%$ to $71 \%$. The significant increase is presumably due to the interaction between the methoxy group and the SBA surface and the resulting accessibility to chiral environment of the chiral catalytic sites on the SBA surface. These results are comparable to those of the homogeneous system using $N$-alkyl ephedrine. ${ }^{5 a}$

Next, the efficiency of SBA-15-supported norephedrine 2 was assessed in ruthenium-catalyzed asymmetric transfer hydrogenation of ketones. ${ }^{9}$ The chiral ruthenium catalyst was generated in-situ by mixing $\left[\mathrm{Ru}\left(\eta^{6} \text {-arene }\right) \mathrm{Cl}_{2}\right]_{2}$ and supported ligand $2(\mathrm{Ru}:$ ligand $=1: 2)$ in 2-propanol at 80 ${ }^{\circ} \mathrm{C}$ for $1 \mathrm{~h}$. The catalyst afforded $(S)$-secondary alcohols with

Table 3. Asymmetric transfer hydrogenation of ketones ${ }^{a}$

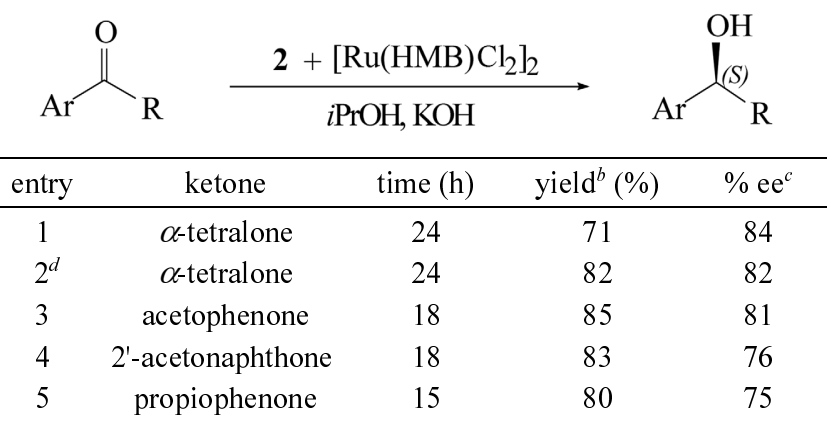

${ }^{a}$ The reaction was carried out at RT; ketone : Ru : ligand $\mathbf{2}=100: 1: 2$. ${ }^{b}$ Measured as \%-conversion into the product by GC. ${ }^{c}$ Determined by HPLC analysis using Chiralcel OB-H column. ${ }^{d}\left[\mathrm{Ru}(p \text {-cymene }) \mathrm{Cl}_{2}\right]_{2}$ instead of $\left[\mathrm{Ru}(\mathrm{HMB}) \mathrm{Cl}_{2}\right]_{2}$ was used. high ee's of up to $90 \%$ in reasonable conversions. The reaction conditions and results are summarized in Table 3. The enantioselectivity seems to depend on the structure of the substrate. As the bulkiness of the alkyl substituent increases, the degree of ee was lowered. [Ru(hexamethylbenzene) $\left.\mathrm{Cl}_{2}\right]_{2}$ as a $\mathrm{Ru}(\mathrm{II})$ source gave somewhat higher ee than $\left[\mathrm{Ru}(p \text {-cymene }) \mathrm{Cl}_{2}\right]_{2}$. It should be noted that SBA-15supported ligand $\mathbf{2}$ is as effective as comparable free (-)ephedrine ligand $^{6 \mathrm{a}}$ in terms of enantioselectivity.

In conclusion, we have shown that the SBA-15 can be served as a potential support for the heterogeneous chiral ligand. Our studies partially support the possibility of achieving high reactivity and enantioselectivity in heterogeneous systems. Further synthesis of SBA-supported chiral ligands and their use to asymmetric catalysis are underway in our laboratory.

Acknowledgment. We appreciate Nano Center for Fine Chemicals Fusion Technology for financial support.

\section{References}

1. (a) Hodge, P.; Sherrington, D. C. Polymer-Supported Reactions in Organic Synthesis; Wiley-Interscience: New York, 1980. (b) Smith, K. Solid Supports and Catalysts in Organic Synthesis; Ellis Horwood and Prentice Hall: New York, 1992.

2. Leadbeater, N. E.; Marco, M. Chem. Rev. 2002, 102, 3217.

3. (a) Bhalay, G.; Dunstan, A.; Glen, A. Synlett 2000, 12, 1846. (b) Song, C. E.; Lee, S.-g. Chem. Rev. 2002, 102, 3495.

4. Zhao, D.; Huo, J.; Feng, J.; Chmelka, B. F.; Stucky, G. D. J. Am. Chem. Soc. 1998, 120, 6024.

5. (a) Chalone, P.; Perera, R. Tetrahedron Lett. 1987, 26, 3013. (b) Priego, J.; Mancheno, O. G.; Cabrera, S.; Carretero, J. C. J. Org. Chem. 2002, 67, 1346; (c) Park, D. H.; Choi, H. J.; Lee, S.-g. Bull. Korean Chem. Soc. 2003, 24, 1559. (d) Fontes, M.; Verdaguer, X.; Sola, L.; Pericas, M.; Riera, A. J. Org. Chem. 2004, 69, 2532. (e) Jin, M.-J.; Kim, Y.-M. Bull. Korean Chem. Soc. 2005, 26, 215.

6. (a) Takehara, J.; Hashiguchi, S.; Fujii, A.; Inoue, S.-I.; Ikariya, T.; Noyori, R. Chem. Commun. 1996, 233. (b) Noyori, R.; Yamakawa, M.; Hashiguchi, S. J. Org. Chem. 2001, 66, 7931. (c) Mogi, M.; Fuji, K.; Node, M. Tetrahedron; Asymmetry 2004, 15, 3715.

7. Soai, K.; Watanabe, M.; Yamamoto, A. J. Org. Chem. 1990, 55, 4832.

8. General procedure: To a solution of ligand $1(160 \mathrm{mg}, 0.62 \mathrm{mmol} /$ $\mathrm{g})$ in hexane $(1.6 \mathrm{~mL})$ was dropwise added diethylzinc $(2 \mathrm{~mL}, 1.0$ $\mathrm{M}$ in hexane) at $0{ }^{\circ} \mathrm{C}$. The mixture was allowed to warm to RT. Aldehyde $(1.0 \mathrm{mmol})$ was then added and the reaction mixture was stirred at room temperature, observing the progress of the reaction by GC. After work up, the residue was purified by column chromatography and the e.e. was measured by HPLC on a Chiralcel OD-H column.

9. General procedure: A mixture of $\left[\mathrm{Ru}(\mathrm{HMB}) \mathrm{Cl}_{2}\right]_{2}(3.4 \mathrm{mg}, 0.005$ $\mathrm{mmol})$ and supported ligand $2(30 \mathrm{mg}, 0.65 \mathrm{mmol} / \mathrm{g})$ was heated in dry 2-propanol $(1 \mathrm{~mL})$ at $80{ }^{\circ} \mathrm{C}$ for $50 \mathrm{~min}$. After the solution was cooled to room temperature, a solution of aromatic ketone $(1.0 \mathrm{mmol})$ in dry 2-propanol solution $(10 \mathrm{~mL})$ was added, followed by $\mathrm{KOH}(0.5 \mathrm{~mL}, 0.1 \mathrm{M}$ in 2-propanol). The reduction was conducted at room temperature under nitrogen. The reaction was monitored by GC and the e.e. was measured by HPLC on a Chiralcel OB-H column. 